\title{
Campos de Xerez: palco de lutas e conflitos pela
exploração da mão-de-obra indigena.
}

Sandra Nara da Silva Novais
Aguinaldo Rodrigues Gomes
****

Este ensaio propõe apresentar os fatores históricos que inviabilizaram a perpetuação do projeto assuncenho-castelhano no atual território sul-mato-grossense, abrangendo especificamente a região que na toponímia colonial foi denominada "Campos de Xerez", a qual abrangia uma extensa área situada entre os rios Taquari e Apa, limitando-se a Oeste pelo rio Paraguai e a Leste pela Serra de Maracaju. Sobre os "Campos de Xerez", instalou-se a Província Jesuítica do Itatim. A destruição dessa província ocorreu em 1648, logo após o desaparecimento da cidade colonial espanhola Santiago de Xerez, em 1632, devido às sucessivas investidas dos bandeirantes paulistas na primeira metade do século XVII, sobretudo a da grande bandeira comandada por Raposo Tavares, em 1648, para o que muito contribuíram as desavenças entre jesuítas e colonos xerezanos, que disputavam a exploração da mão-de-obra indígena local. Tais desavenças passado colonial ibérico da região sudoeste do atual Estado de Mato Grosso do Sul pode ser compreendido e dividido, para melhor analisá-lo e entendê-lo, em dois compartimentos cronológico-conjunturais, os quais evidenciam momentos específicos da formação de sua história, isto é, o contexto abarcado pela colonização castelhana - paraguaia e a colonização luso-paulista. O primeiro período corresponde, sobretudo aos séculos XVI e XVII, com a fundação por assuncenhos, no ano de 1600 , de um pequeno núcleo colonial denomi-

\footnotetext{
* Artigo originalmente apresentado nas XIII Missões Jesuíticas - Jornadas Internacionais - Fronteiras e Identi-dades: povos indígenas e missões religiosas, realizada na Universidade Federal da Grande Dourados - UFGD com o título: Bandeirantes, Xerezanos e Jesuítas: confrontos pela exploração da mão-de-obra indígena nos "Campos de Xerez". Esta versão incorpora as sugestões e considerações fruto dos debates que possibilitam ampliar e estabelecer um novo olhar sobre a problemática em questão.

** Mestre em História pela Universidade Federal do Mato Grosso do Sul e Doutoranda em Educação pela Uni-versidade Federal de São Carlos. E-mail:novaisnara@hotmail.com

*** Graduado em História e Mestre em Educação Brasileira pela Universidade Federal de Uberlândia, professor da Universidade Federal do Oeste do Pará (UFOPA). E-mail: aguinaldorod@gmail.com
} 
contribuíram para a eficiência das incursões portuguesas, que acabaram por enfraquecer os pólos de colonização espanhola nos "Campos de Xerez".

Palavras-chave: Mato Grosso colonial. Mãode-obra indígena. Campos de Xerez.

This paper proposes to present the historical factors that made the perpetuation of project assuncenho-Castilian in current territory sulmato-grossense, covering specifically the region in toponymy colonial was named "Campos of Xerez", which covered a large area situated between the rivers Taquari and Apa, limiting the West by the rio Paraguay and Serra de Maracaju. On the "Campos of Xerez" settled the Jesuit Province of Itatim. The destruction of this province occurred in 1648, shortly after the disappearance of Spanish colonial city Santiago of Xerez, in 1632, owing to successive invested of the members of the Bandeiras from São Paulo in the first half of the 17th century, mainly of large flag commanded by Raposo Tavares, in 1648 , for that very contributed the estrangement between Jesuits and settlers xerezanos, that disputed the exploration exploitation of the local indigenous labor. Such disagreements have contributed to the efficiency of Portuguese incursions, which ultimately weaken the poles of Spanish colonization in "Campos of Xerez".

Key words: Colonial Mato Grosso. Hand-ofindigenous work. Campos of Xerez. nado Santiago de Xerez. Enquanto que o segundo inicia-se timidamente nas primeiras décadas do século XVII, vindo a consolidar-se de forma definitiva durante os anos seguintes, culminando, na segunda metade do século XVIII, com a instalação de um sistema fortificado de ocupação, expresso pelos fortes: Iguatemi, Coimbra, Albuquerque e Miranda.

$\mathrm{O}$ artigo tem por objetivo apresentar e compreender os fatores históricos que inviabilizaram a perpetuação do projeto assuncenho-castelhano, no território, hoje sul-mato-grossense, abrangendo especificamente a região que na toponímia colonial, foi denominada "Campos de Xerez", evidenciando os entraves que impossibilitaram o desenvolvimento do projeto pensado pelos xerezanos para a região. Consideramos que a historiografia sul-americana ao olhar os fenômenos históricos ocorridos no interior do continente, a faz, predominantemente, ou sob uma ótica atlântica ou andina. Dessa forma, há uma ausência, um esvaziamento, das explicações históricas mais detalhadas no que diz respeito aos eventos ocorridos na Bacia Platina, sobretudo nas regiões banhadas pelo Médio e Alto Paraguai. É o caso, por exemplo, da formação da fronteira oeste do Brasil e dos episódios relacionados à conquista, colonização e ocupação do espaço sul-mato-grossense, nos séculos XVI e XVII. As abordagens da historiografia brasileira, com algumas respeitáveis exceções, situam a dinâmica histórica, de forma unila- 
teral, onde os fatos históricos ocorridos nesse espaço territorial, em sua grande maioria, costumam ser vistos como desdobramento do movimento bandeirante luso-paulista, permanecendo o contexto histórico marcado pela presença colonial espanhola-assuncenha pouco conhecido.

Entre as principais fontes históricas consultadas foram de fundamental importância as informações existentes nos relatos dos cronistas que estiveram na região entre os séculos XVI e XVII entre eles Ulrich Schmidel "Relatos de La Conquista del Rio de La Plata y Paraguay 1534-1555"1, Álvar Nuñez Cabeza de Vaca "Comentários" e Ruy Diaz de Guzmán "Anales del Descobrimento y Conquista del rio de de La Plata"2. Tais narrativas oferecem elementos imprescindíveis para compreendermos o conjunto de representações que se fazia de uma realidade espacial totalmente desconhecida pelos europeus, a qual era habitada por povos por eles, considerados selvagens e que apresentava uma geografia carregada de incertezas e imprecisões. Em tais relatos encontramos referências importantes sobre os povos indígenas que habitavam o Paraguai antes da chegada do europeu e que desempenharam um papel significativo na conquista e na consolidação do modelo colonizador. Referimos-nos tanto às etnias que estabeleceram alianças com os espanhóis e colaboraram com a conquista, unindo-se a estes por laços de parentesco dando origem à intensa mestiçagem, principalmente em Assunção e arredores, como também, aos grupos indígenas que optaram em resistir à colonização por meio de acirradas guerras contra os invasores, o que resultou na desterritorialização e no extermínio de grande contingente populacional indígena da América do Sul.

Utilizamos também da documentação Jesuítica referente às Províncias Missioneiras do Guairá e do Itatim reunidas na Coleção De Angelis. O primeiro Tomo inclui documentos relativos ao Guairá, cobrindo o período entre 15491640 têm como título "Jesuítas e Bandeirantes no Guairá". O segundo Tomo referente ao Itatim, aborda os episódios ocorridos entre 1596-1710, com o título “Jesuítas e Bandeirantes no Itatim”. Utilizamos-nos também dos trabalhos de his-

\footnotetext{
${ }^{1}$ SCHMIDEL, Ulrico. Relatos de la conquista del Rio de la Plata y Paraguay, 1534 - 1554. Madrid: Alianza Editorial, 1986.

${ }^{2}$ GUSMÁN, Ruy Diaz de. Anales del descubrimento, poplación y conquista del rio de la Plata. Paraguai: Ediciones Comunero, 1980.
} 
toriadores representantes de distintas gerações historiográficas, tanto no Brasil, como na Argentina e no Paraguai. Entre os autores clássicos, que se dedicaram a esclarecer alguns aspectos da conquista do interior das terras da América do Sul pelos espanhóis, destacamos Enrique de Gandia (Argentina), Jaime Cortesão (Portugal), Sérgio Buarque de Holanda (Brasil) e Roberto Quevedo (Paraguai). Preocupados com a mesma temática, nos utilizamos ainda das abordagens desenvolvidas por historiadores tais como Uacury Ribeiro de Assis Bastos ${ }^{3}$, Regina Gadelha $^{4}$, Maria de Fátima Costa ${ }^{5}$, Paulo Marcos Esselin ${ }^{6}$ e Otávio Canavarros ${ }^{7}$, que olharam para o fenômeno aqui abordado utilizando-se de um criterioso instrumental teórico/metodológico.

Nesta análise recorremos aos episódios que caracterizam o ano de 1600, o qual é marcado pelos esforços e trabalho dos espanhóis e dos demais moradores de Santiago de Xerez em garantir que o núcleo urbano prosperasse. Devido às dificuldades enfrentadas, os habitantes de Xerez não tinham mais dúvidas de que insistir em manter a cidade, no local em que havia sido fundada pela primeira vez, segundo Martins ${ }^{8}$, sobre algum ponto da margem direita do baixo curso do rio Muney, hoje Ivinheima, no atual município sul-mato-grossense de Naviraí, por Ruy Diaz de Guzmán, no ano de 1593, era inviável. Frequentes eram os ataques e assaltos promovidos pelas tribos indígenas vizinhas ao novo núcleo, frustrando, desse modo, a iniciativa colonial espanhola xerezana de que a cidade pudesse prosperar. Tais ataques refletiam as tentativas e os esforços, por parte dos índios, de inibir e até mesmo de impossibilitar a presença dos colonizadores espanhóis em seus domínios. Isso porque, os índios, temiam perder

${ }^{3}$ BASTOS, Uacury Ribeiro de Assis. A expansão territorial do Brasil Colônia. São Paulo: Faculdade de Filosofia, Letras e Ciências Humanas, USP. Depto. de História, 1979.

${ }^{4}$ GADELHA, Regina Maria A. F. As missões jesuíticas do Itatim: um estudo das estruturas sócioeconômicas coloniais do Paraguai (séc. XVI e XVII). Rio de janeiro: Paz e Terra, 1980.

${ }^{5}$ COSTA, Maria de Fátima. História de um país inexistente: o pantanal entre os séculos XVI e XVIII. São Paulo: Estação Liberdade; Kosmos, 1999.

${ }^{6}$ ESSELIN, Paulo Marcos. A gênese de Corumbá: confluência das frentes espanhola e portuguesa em Mato Grosso (1536 - 1778). Campo Grande, MS: Ed. UFMS, 2000.

${ }^{7}$ CANAVARROS, Otávio. O poder metropolitano em Cuiabá (1727 - 1752). Cuiabá: Ed.UFMT, 2004.

${ }^{8}$ MARTINS, Gilson Rodolfo. Santiago de Xerez: uma problemática para a arqueologia histórica. Asunción: Anuário de la Academia Paraguay de la História. V. XLII, 2002. 
seus respectivos territórios, ou serem obrigados a se submeter às determinações do vencedor, sistema das incomiendas, caso o domínio espanhol se consolidasse na região.

Frente à resistência indígena na tentativa de garantir que o novo povoado prosperasse, e que a cidade de Santiago de Xerez, recém construída, pudesse vir a se tornar um ponto de referência dos espanhóis naquela região, Ruy Diaz de Guzmán tratou de manter-se em paz e justiça com todos os moradores. A cerimônia de fundação da cidade se realizou no dia 24 de março de 1593 e foi lavrada em Ata pelo escrivão Bartolome Garcia, nos seguintes termos:

Por la conversión de los naturales y a la magestad del rey Felipe "de aver ampliado su real Corona e patrimonio en su real nombre por virtud de los poderes a mi dados consedidos y traspassados por el general Alonso de Vera y Aragón"... "me a parecido fundar una ciudad en lugar que mas acomodado fuese para ello, y habiendolo mirado y atentamente e para ello corrido mucha parte, finalmente a parescido ser el mejor e mas acomodado y suficiente este que al presente estamos ques riveras del dicho río de San Salvador (Ivinheima) que dista de puerto de San Matias media légua, por ser en comarca de todos los yndios naturales"... "lugar apazible llano, apartado de ciénagas e buenos campos para los gados e tierras para labanzas"... "la qual intitulo y nombro de Santiago de Xerez y mantenerle en paz y justicia a todo los vezinos y moradores. ${ }^{9}$

De acordo com a Ata de fundação de Xerez, no mesmo dia o general Ruy Diáz de Guzmán nomeou o cabildo e regimiento da cidade. Foram designados por primeiros regidores: Pedro Hurtado de Mendoza, Domingo Machado, Juan de Alvear de Zuñiga, e Francisco de Escobar. Imediatamente o cabildo Xerezano designou Francisco de Morinigo como procurador geral de Xerez. No mesmo dia, Guzmán nomeou Joan de Guzmán alferez e cavaleiro da cidade e de seus distritos. Juntos iniciaram então a construção de um forte para garantir a defesa da nova povoação, e os demais moradores iniciaram a construção das primeiras casas. Porém os primeiros anos de existência desse núcleo colonial não foram

\footnotetext{
${ }^{9}$ Roberto Quevedo transcreveu parte do pronunciamento de Guzmám que foi lavrado em Ata, pelo escrivão Bartolome Garcia na ocasião da cerimônia de fundação de Santiago de Xerez. O documento segue destacando que Guzmán instituiu a pena de morte para aqueles que desamparassem a cidade e solicitou ao rei que lhes enviasse soldados, fidalgos, cavaleiros e homens bons para que pudessem construir um forte e proteger a cidade. (QUEVEDO, Roberto. Fundacion de Santiago de Xerez. In: “Anuario de la Academia Paraguaya de História”. Asunción, vol. n XL - XLI - 2000 -2001 p. $34-35)$.
} 
fáceis para os colonos e nem mesmo para os índios. Período de secas, isolamento, ataque de insetos, perdas de colheitas, insubordinação dos indígenas que se opunham a presença castelhana em seus territórios, foram fatores que levaram ao fracasso a experiência colonizadora xerezana nesse local.

O padre Lozano, na carta Ânua de 1760, afirmou que a cidade de Santiago de Xerez, em Nueva Viscaia, nome pelo qual, anteriormente Irala, governador do Paraguai, havia reconhecido a província dos Nuarás, e que Guzmán nomeou, posteriormente, de Nueva Andaluzia, encontrava-se em grandes dificuldades. Não conseguiam dispor os moradores de Xerez, nem mesmo de padres para fazer a conversão dos indígenas. Segundo Lozano:

La Ciudad de Santiago de Xerez en la Nueva Viscaya, que era la Prova . De los Nuaras la poblo ã pedimento de dhos naturales el Gen. Ruy Diaz de Guzmán com plenos poderes el ano de 1593 y los Nuaras acudian com sus personas e hijos è mugeres al servicio de los Españoles sin ser forzados. El Sacerdote que fue â dha poblacion no se detuve alli mas que dos meses en que baptizó mas de dos mil Yndios, varones, mugeres y niños. No tuvieron despues Sacerdote Hasta la Quaresma de 1593. Pero passada ella se salio dho Sacerdote sin querer ir outro alguno assi por no tener ornamentos como por no tener estipendio. muriendo muchos Españoles y naturales sin confession. Distaba su sitio primitivo noventa leguas de la Assumpcion y ã la banda del Brasil. Estaba de alli cincuenta leguas de la Ciudad Real del Guayrá cuio Paroco murio por los años de 1582 y solo desde el año de 1590 tuvieron dhos Guayreños recurso p. ${ }^{\text {a }}$ que

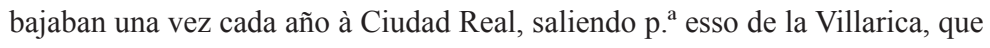
está otras cincuenta leguas mas arriba azia el Brasil. Los otros yndios de Xerez eran Conumyais, y Cuataguás que com los Nuaràs por falta de doctrinas se bolvieron ã sus ritos antiguos y estaban muchos rebelados. Representò todo esto â la Real Aud ${ }^{a}$ de Charcas Geronimo Lopes Procur. de Xerez y Protector de sus naturales pidiendo se les diesse sacerdote, ornamentos com estipendio de la Caxa Real y lo concedio por Provision de 7 de Agosto de 1600. Y por outra despues proveida en 7 de Setempro del mismo año. ${ }^{10}$

Além dos ataques indígenas os colonos xerezanos, em uma petição redigida em Xerez no ano de 1599 solicitando o translado da cidade, afirmavam que padeciam por muito trabalho, fome e enfermidades. Nesse documento os xerezanos

10 "Exame necessário do padre Lozano sôbre o manifesto do padre Vargas Machuca, 1760". (In: CORTESÃO, Jaime. (org.). Jesuitas e Bandeirantes no Itatim. Rio de Janeiro: Biblioteca Nacional - Divisão de Obras Raras, 1952. (Manuscritos da coleção de Angelis) - vol. II, p. 316. 
apresentaram as autoridades superiores as principais características geográficas, econômicas e sociais do lugar onde se encontravam estabelecidos, salientando que em tais condições, devido a precariedade imposta pela adversidade de um ambiente extremamente hostil, parecia-lhes impossível garantir o sustento e o desenvolvimento da cidade. Afirmavam ainda, os xerezanos, que caso deixassem de transladar a cidade poderiam perdê-la porque devido às péssimas condições, esta fatalmente se despovoaria. A esterilidade da terra, o clima, a dificuldade em dispor da mão-de-obra indígena eram alguns dos fatores que impediam o desenvolvimento de uma agricultura, ainda que de subsistência, acarretando na falta de recursos que lhes eram convenientes e necessários para garantir o sustento de todos. Afirmavam os xerezanos que dentre as causas principais que faziam desse local inadequado para que pudessem ali permanecer, destacavam-se:

[...] la primera ser el clima y costelacion enferma por estar thodabia debajo del tropico la segunda aber muy pocos naturales sercanos y los que ay tan debiles y de poca utilidad que no son sufisientes a sustentar esta dicha ciudad y lo outro estar muy apartada de las poplaciones de los yndios que ay en la provincia asi [Roto] mo ser la tierra muy ceca y faltandole el te[mpo]al de las aguas que de ordinario falta quando es nesesaryo se pierden y consumen las simenteras y no se haze cozecha la ultyma y mas perjudicial que en esto dicha ciudad questa anjambrada dellas por cya cauza no se na podido criar viñas y sustentar guertas ny tener arboledas de frutas de Castilla ny de la tierra quales penurias viztas por las personas que aca bienen a bivir y los que pretendian despues benir no se anyman ny [roto] ponen a ello y el mayor y mas principal que desto resulta es el careser del consuelo espiritual porque no ay nyngun saserdote que quiera benir ny acistir en esta dicha ciudad... ${ }^{11}$

Ao se deparar com inúmeras dificuldades, as quais impediam a sobrevivência e a manutenção do núcleo urbano xerezano no local onde se encontrava estabelecido, o próprio Ruy Diaz de Guzmán, após ter voltado de uma viagem ao Guairá, onde fora apaziguar os conflitos e enfrentamentos ocorridos naquela província, e encontrado a cidade de Xerez em precárias condições, buscando atender às reivindicações dos colonos, tratou de criar, junto aos demais moradores de Xerez, um movimento, solicitando do governador do Paraguai Hernadarias de Saavedra, permissão para que pudessem transladar a cidade.

11 " 1599 , setiembre 26, Santiago de Jerez. El procurador Anton Bernal y vecinos de la ciudad presentan al cabildo un petitorio para que se traslade la ciudad y se nombre un procurador para ir a Asunción.” In: Anuario de la Academia de la Historia. Vol. XL - XLI, 2000 - 2001, p. 761. 
Ao se referir ao local onde foi fundada pela segunda vez a cidade de Santiago de Xerez, Aguirre, assim como o padre Lozano, afirma que se encontrava situado, este núcleo urbano, sobre o rio Mbotetey, a aproximadamente 30 léguas, acima, de sua confluência com o Miranda e que tinham os espanhóis por vizinhos os moradores da província do Guairá. Xerez se encontrava localizado na região banhada pelo rio Mbotetey, também denominado na toponímia colonial como Bitetey ou, ainda, rio dos Apóstolos e, mais tarde, Mondego, em algum ponto na área compreendida, atualmente, pela bacia dos rios Miranda e Aquidauana, na parte não inundável do Pantanal sul-mato-grossense, o que nos permitiu, segundo as fontes consultadas, identificar os arredores, ou seja, a área conjunta dos atuais municípios de Miranda e Aquidauana, como "Campos de Xerez"12.

O translado da cidade, segundo Aguirre, ocorreu:

En tiempo del General D. Francisco de Beumont y Navarra fué cuando se transladó Santiago ao Mbotetei entre las encomiendas de Niguarás reducidos por el célebre Juan de Garay. Pertenecia entonces una de ellas à Hernandarias, como otras à diferentes vecinos de la Asuncion, entre quienes la de Bartolomé Gomes estaba muy cerca de la misma poblacion. Por esto el procurador Juan Gonzales de $\mathrm{St}^{\mathrm{a}}$. Cruz pidió à la contradijese y mandase despoblar. Las resultas que tuve esta solicitud las ignoro, y solo por otros documentos se infiere que Xerez se legitimó y permaneció. ${ }^{13}$

Aguirre segue afirmando, de acordo com o documento acima citado, que os moradores de Assunção, lamentando os prejuízos que teriam com a instalação de uma cidade junto aos índios Niguarás, os quais deveriam lhes servir como encomiendados, tentaram fazer com que novamente Xerez fosse despovoado. Para tal, os assuncenhos, juntamente com alguns xerezanos, como Juan de Molina e Miguel Lopez Barreda, ambos citados por Aguirre, apresentavam como justificativa, para a mudança do núcleo urbano, relatos onde constavam as dificuldades e a infelicidade em que viviam os habitantes de Xerez. Informa-nos ainda, o referido documento, que no ano de 1605, Andres Diaz, tenente de Ruy Diaz e Guzmán, ordenou um ataque contra os índios que até aquele momento se encontravam em paz com os colonizadores estabelecidos em Xerez: "Decia á

\footnotetext{
${ }^{12}$ MARTINS, Gilson Rodolfo. Op. cit., p. 246.

${ }^{13}$ AGUIRRE, J. F. "Diário del Capitán de Fragata de la Real Armada”. In: Revista de la Biblioteca Nacional, Argentina, Buenos Aires, Tomo II, n. 47 e 48, 1950, p. 308.
} 
mas que los Ñiguaras se habian sublevado y muerto 80 persona del servício de los españoles de la referida ciudad que por no tener bastimentos andaban por los montes manteniéndose de raices y frutas silvestres." 14

De acordo com as informações de um jesuíta anônimo, sobre as cidades do Paraguai, datada do ano de 1620, a cidade de Santiago de Xerez, na Nueba Viscaya, encontrava-se localizada a mais de cem léguas de Assunção, situada sobre o rio Boteteí, rio de muito peixe, afluente do Paraguai e navegável em todo seu percurso. Entre os povos que habitavam a região, cita os Guanchas, os quais se encontravam divididos em três povoados somando aproximadamente mil índios. Além dos Guanchas cita os Guató, que se encontravam divididos em dois povoados, eram em torno de mil índios. Por último cita os Guapís, comunidade indígena formada por uns cem índios. Todas essas nações indígenas falavam línguas diferentes. Afirma que os Guetu habitavam entre os rios Taquari e Boteteí em grande número. Encontrava-se o primeiro povoado desses Guetu a uma distância de quinze léguas de Xerez. Mais adiante, no rio Taquari, afirma ter encontrado cerca de mil índios Guarani, habitantes dos “Campos de Xerez”. De acordo com o documento citado:

Ay quarenta leguas desde Xerez alla por el camino de la cordillera y por abajo abra ssenta leguas, de ali adelante no se há descubierto deiçen que há muchissima gente. Indios Ñuguaras que estan de paz en Xerez seran mill y docientos poco mas o menos y no ay mas gente Ñuara que esta quatro leguas de Xerez hacia el Paraguay poco mas o menos esta el primer pueblo de los Itatines gente Guarani que he dicho estan encommendados en la Assunpçion. ${ }^{15}$

Encontramos em um testemunho do padre Antonio de Acosta de Souza, escrito em Santiago de Xerez, no ano de 1600, algumas referências sobre o lugar para onde a cidade deveria ser transladada. Afirmou o padre, nesse documento, que se tratava de uma terra fértil, de bons pastos, montes e rios. Particularmente o rio Botetey, o qual, segundo ele, também era chamado de rio dos Apóstolos. Relatou o padre Antonio que o viu com seus próprios olhos, quando acompanhava o capitão Andrez Diaz, em um castigo aos índios indelinquentes, e deparou-se com o rio. Permaneceram por quatro dias no rio Botetey, dispondo de muita caça

\footnotetext{
${ }^{14}$ Idem, ibidem p. 309.

15 "Informe de um jesuíta anônimo sôbre as cidades do Paraguai e do Guairá Espanhóis índios e mestiços. Dezembro de 1620”. (In: CORTESÃO, Jaime. (org.). Op. cit., p. 172).
} 
e pesca. Após seguiram navegando este rio Botetey abaixo, e em poucos dias encontravam-se em Assunção, onde obtiveram notícias de que eram muitos os índios que habitavam por aquela região. Algumas nações eram de índios canoeiros, outras de índios que moravam em terra firme. Eram esses índios lavradores, pescadores e caçadores.

Diogo Ferrer assim descreveu os índios Gualacho que habitavam as proximidades do rio Botetey:

[...] De aqui hazia el Norte sobre y cerca del rio Butetey de esta banda del rio Paraguay ay muchos Gualachos labradores que tienen pueblos fixos y chacaras grandes y en ellas todo lo que tienen los Guaranis. y no diferen en nada dellos sino en la lengua, aunque diz que tambien ellos entre si tienen una lengua o dos universales, y entran a contratar com estos Itatines. tengo escritos dellos mas de veynte pueblos. tienen buen natural y algunos dizen que es aun mejor que el de los Guaranis, tienen mucho arroz que recojen por sus lagunas, y son grandes pescadores. (...) Arriba de estos Gualachos hazia el Nordeste esta el rio Taquary que se desemboca en el Paraguay arriba de los Guayarapos. en este rio ay indios Guaranis que venian antiguamente a contratar com estos Itatines, pero por los Gualachos del rio Butetey que dixe estan entremedios y les estovan el paso no se atreven a venir mas. Mas adelante hazia el nordeste ay otros Gualachos bravos, y hazia el norte estan las Amazonas. ${ }^{16}$

Ao se referir às condições de vida em Xerez, afirma o documento, que eram poucos os moradores de Xerez, todos eles mestiços e qualificados como sendo de baixos pensamentos. "Los vezinos de Xerez casi todos eran mestizos de baxos pensamientos que apenas llegarán â treinta hombres sin aver tenido mas que un Sacerdote que vino del Brasil por $\mathrm{S}^{\mathrm{a}}$. Pablo pocos años antes del dho de 1621 â quien encargaron un partido de Yndios ...". ${ }^{17}$

Diante dos constantes conflitos com os indígenas, o núcleo colonial urbano xerezano, passou por grandes dificuldades. Para manter a cidade, necessitavam que os assuncenhos lhes enviassem constante ajuda de víveres e de gente. Não conseguindo se legitimar e nem se impor na região, os moradores de Xerez, recorriam constantemente a pedir ajuda e socorro ao Governador do Paraguai, que

16 “Ânua do Pe. Diogo Ferrer para o Provincial sôbre a Geografia e Etnografia dos indígenas do Itatim 21 - VIII - 1633”. (In: CORTESÃO, Jaime (org). Op. cit., vol II, p. 47 - 48).

17 "Exame necessário do Pe. Lozano sôbre o manifesto de Pe. Vargas Machuca, 1760". (In: CORTESÃO, Jaime. (org.). Idem, vol II, p. 317). 
se encontrava em Assunção. Consta que Hernandarias de Saavedra, enquanto esteve à frente do governo do Paraguai, enviou ajuda por duas vezes aos colonizadores em Xerez. A primeira, no ano de 1602, sob o comando de Juan de Espinosa e a segunda em 1604, a qual esteve sob o comando de seu pai, de quem havia herdado o mesmo nome. Em 1607, diante da difícil situação dos colonos xerezanos, Hernandarias de Saavedra enviou um ofício ao Rei se referindo a teimosia de Ruy Diaz de Guzmán em fundar Xerez, despovoando Ciudad Real. Nesta expedição consta ainda que:

Tambien en este fué el hijo y ambos socorros llegaron á 60 hombres á mas de sus servicios; pero duraban poco tiempo en Xerez porque se manifiesta la hambre y necessidad que pasaban en tales términos que no podian subsistir. Al regresar los espinosas lo resolvieron por el rio que ay llamaban de Xerez. Se embarcaron com diez hombres y tuvieron á poco de su salida una refriega com los naturales de que salieron bien; pero despues tuvieron outra com los payaguas sin poder-lo remediar en que les fué mal. Ellos y un soldado Diego Moyano escaparon la vida trabajosamente; los demas murieron. ${ }^{18}$

Após constatar as dificuldades em se estabelecer em definitivo o novo núcleo colonial urbano, o procurador de Xerez Bernardino de Espinosa, no ano de 1605, relatou ser impossível à cidade se manter. Justificava Espinosa que Xerez necessitava constantemente de socorros e que, devido à distância, onde se encontrava localizada, os reforços e ajudas solicitadas pelos xerezanos, demoravam muito a chegar. Um outro aspecto, apontado por Espinosa, e que contribuía decisivamente para que Xerez permanecesse isolada é que a própria Assunção se encontrava em grandes dificuldades: "Asuncion se hallaba muy pobre y descarnada y su provincia expuesta á perderse y ser destruida como acababa de suceder á Chile si se confederaban los indios de Xerez com los Payaguas y Guaicurus." 19

Ao se referir especificamente às condições em que se encontrava Assunção, Aguirre faz uma importante observação sobre a importância dessa cidade, enfatizando a relevância que assumiu Assunção para toda a colonização do rio da Prata, e que achamos por bem transcrevê-la:

Esta república erigida entre las calamidades, elevada a matriz de las colonias del rio de la Plata, alcanzó algunos privilegios de metrópoli. Los colonos lle-

\footnotetext{
${ }^{18}$ AGUIRRE, J. F. Op. cit., p. 309.

${ }^{19}$ Idem, ibidem.
} 
varon el uso de la hierva mate y aún le propagaron á otras partes por la escasa comunicacion de aquel tiempo en España. A mas de la hierba, el tabaco, el dulce, el vino, el trigo el aguardiente y otros renglones les subministraba la Asuncion, que aunque fuesen de corta cantidad eran algunas ventajas para su subsistência. ${ }^{20}$

As circunstâncias em que se encontravam envolvidos os colonizadores de Xerez em muito se diferenciava dos de Assunção em seu período expansionista. Xerez nunca conseguiu assumir a importância que obteve Assunção para a conquista do Rio da Prata. Além dos fatores anteriormente citados, as desavenças e rivalidades entre Hernandarias de Saavedra, governador do Paraguai e Ruy Diaz de Guzmán, tenente e governador de Xerez, a qual já era de longa data, contribuíam para que Hernandarias solicitasse constantemente o despovoamento de Xerez. A cidade de Xerez era vista por Hernandarias como intrusa, por estar localizada entre os índios que haviam sido anteriormente encomendados por Juan de Garay aos povoadores de Assunção. No entanto, mesmo enfrentando inúmeras dificuldades, o núcleo colonial urbano xerezano se conservou e permaneceu no local para onde havia sido transladado, no ano de 1600 .

A permanência de Xerez sobre o Mbotetey até o ano de 1632, no entanto, refletiu os esforços e a coragem dos colonos xerezanos em enfrentar as constantes rebeliões indígenas e submeter os poucos moradores e também os soldados que se encontravam na cidade. Os quais, na primeira oportunidade, devido as enormes dificuldades, abandonavam Xerez. “... los soldados que se na ydo desta ciudad se na ydo por no poderse sustentar en el comer ny bestir e que sabe este dicho testigo que algumas rayzes que se comyan en esta tierra y yervas e frutas silbestres van en desmynusion que algunas vezes la desean comer y falta." ${ }^{21}$.

$\operatorname{Bastos}^{22}$, ao tecer considerações sobre os motivos que determinaram o estabelecimento, pelos espanhóis, de um núcleo urbano no Itatim, afirma que esta fundação está relacionada ao fato de que os espanhóis pretendiam se instalar nessa região porque sabiam da possibilidade de atingir o Peru pelo Itatim. Pois

\footnotetext{
${ }^{20}$ Idem, ibidem, p. $354-355$.

21 "1600, noviembre 6. Santiago de Jerez. Testimonio del padre Antonio de Acosta de Souza". In: Anuario de la Academia Paraguaya de la Historia. Vol XL - XLI, 2000-2001, p. 776.

${ }^{22}$ BASTOS, Uacury Ribeiro de Assis. Op. cit
} 
essa rota já havia sido anteriormente percorrida e comprovada. Assim esclareceu Bastos:

Suas conexões com o Peru, conhecidas e comprovadas, através das diversas expedições que cruzaram o Chaco partindo de Itatins, foram fatores decisivos para a fundação de Xerez. Também o problema das encomiendas de índios dos assuncenhos foi motivação importante na penetração de colonos espanhóis ou seus descendentes, no Itatim ${ }^{23}$.

Quanto ao modo de vida que se estabeleceu em Xerez, Gadelha ${ }^{24}$, nos esclarece que mesmo tendo escravizado os índios Ñuara, estes viviam sempre revoltados contra os colonos xerezanos. Um exemplo de que esses índios nunca aceitaram a presença colonial espanhola em seu território, são as inúmeras revoltas dos Itatins nesse período. Além dessas revoltas, outro fator que inviabilizou a permanência de Xerez no território do Itatim é que este núcleo colonial se encontrava isolado das mais importantes rotas comerciais, o que impedia o desenvolvimento de sua economia. Devido ao fato de se encontrar afastada, era difícil sua comunicação com Assunção. A cidade ainda era vítima dos constantes ataques por parte dos Paiaguá e dos Guaicuru.

Diante dessas circunstâncias afirma Gadelha que:

[...] apesar das tentativas para manter a vila, esta definhava, não restando mais que quinze homens brancos no local, no início do século XVII. Manter Xerez representou ato de coragem e heroísmo da parte dos que se sacrificaram, permanecendo no local, pois quem mais tirava lucro da situação era, na verdade, alguns encomenderos assuncenhos, desejosos de se aproveitar da mão-de-obra em potencial, representada pelos índios dessa região ${ }^{25}$.

$\operatorname{Costa}^{26}$, enfatizou que muito embora a localização do novo núcleo colonial tenha sido descrita por seu fundador como de boas condições, na prática a realidade mostrava indícios de que havia uma dose de otimismo um tanto exagerada por parte de Guzmán, devido ao fato de que:

Santiago de Xerez não conseguiu prosperar, nunca chegou a ser um grande núcleo populacional. Em 1605 contava apenas com quinze homens capazes de to-

\footnotetext{
${ }^{23}$ Idem, ibidem, p. 70.

${ }^{24}$ GADELHA, Regina Maria A. F. Op. cit., 1980.

${ }^{25}$ Idem, ibidem, p. 81-82.

${ }^{26}$ COSTA, Maria de Fátima. Op. cit., 1999.
} 
mar armas; carecia de padres e de eclesiásticos. Falava-se de tanta miséria que seus habitantes sobreviviam alimentando-se de raízes. Esta precariedade devese, entre outras coisas, à inexistência de comércio regular, à difícil comunicação com Assunção e aos constantes ataques de Payaguá e Mbayá-Guaykurú. Em vista disso, o próprio governo assuncenho solicitou seu despovoamento. Contudo, em meio a esta miséria, conseguiu subsistir até $1632^{27}$.

De acordo com as fontes consultadas encontramos muitas evidências de que a cidade de Santiago de Xerez, ao contrário das descrições um tanto otimistas, feitas por seu fundador, Ruy Diaz de Guzmán, desde a sua primeira fundação, enfrentou muitas dificuldades para se manter. Encontramos uma descrição feita por Guzmán em que ele destaca as qualidades de Xerez, na tentativa de justificar sua fundação:

Esta ciudad de Santa Cruz está com la de Jerez de leste á oeste, 60 leguas de rio, y la de Jerez 30 a mano derecha, a cual está ciento y tantas leguas de la Asuncion. Tiene su fundacion sobre un rio navegable y caudaloso, llaman los naturales Botetey, y está de la esquinoccial 20 grados, tiene muy buenas tierras, está dividida en alta y baja hay en ella muchas naciones de indios que todos son labradores. Los que habitan en lo alto, se llaman Cutaguas y Curumias, todos de una costumbre y lengua, gente nien inclinada, y no muy bárbara; no usan ningun jénero de brebaje que los embriague, aunque los deabajo tienen muchos: hablan diferentes lenguas, y están poplados entre rios y lagunas, los cuales ademas de las cosechas de legumbres que cojen, tienen cerca de las lagunas tanto arroz silvestre, de que hacen muy grandes trojes, y silos, que siempre se hallan provistos de este gran sustento: cojen en toda aquella provincia mucho algodon, que sin beneficio alguno se dá en gran cantidad, y es tanta la miel de abeja silvestre, que todos los montes y árboles tienen sus colmenas y panales de que sacan gran cantidad de cera, y se aprovechan de ella en las gobernaciones del Paraguay y Tucuman. Es abundante de pastos, donde se cria todo jénero de ganados, y muy f'rtil de pan y vino, y de todas las legumbres y semillas de Castilla. Finalmente es una provincia de mucha estima y de las mas nobles y ricas de aquella gobernacion, por que á la falda de una Cordillera, que parte aquella tierra en alto e baja y viene bojeando desde el Brasil, se han hallado minerales de oro com muchas muestras de metales de plata ${ }^{28}$.

${ }^{27}$ Idem, ibidem, p. 45.

${ }^{28}$ GUSMÁN, Ruy Diaz. Anales del decubrimiento, poplacion y conquista del rio de la Plata. Paraguai: Ediciones Comunero, 1980, p. 29-30. 
Muito embora Guzmán insista em atribuir e ressaltar as qualidades de Xerez, o fato é que a cidade não prosperou. Sem recursos, passou a viver precariamente, sendo constantemente ameaçada pelos Guaicuru cavaleiros e pelos Payaguá canoeiros, os quais dificultavam as comunicações entre Xerez e Assunção pelo rio Paraguai. Com a aproximação dos paulistas instalando povoados no rio Paraná acima, em busca da mão-de-obra indígena Guarani dos Campos de Xerez e do Itatim, se intensificaram os riscos de se perder, para os portugueses, o povoado de Xerez.

Encontramos em uma carta Ânua as seguintes referências sobre o Itatim:

La Provinçia del Itatin esta este rrio del Paraguay arriba. Toda es gente Guarani, estos indios han sido siempre quietos nunca han hecho mal a español, quieren sacerdotes, no se los han dado. Muchos há que yendo y viniendo a Santa Cruz de la Çierra passaron por alli españoles alvergaronlos bien batizaron algunos y dejaron raçonable cantidad de mestizos. Junto a estos indios estan las minas de azogue que diçen han hallado y tambien dicen que ay plata cerca de ellas. Como ninguno governador toma esto a pechos todo se estara esta provinçia distante de la çiudad de la Assumpçion çien leguas poco mas o menos. ${ }^{29}$

Diante das constantes ameaças, o procurador de Xerez Alonso Riquelme de Guzmán, solicitou ao governador de Assunção que lhes enviasse algum socorro, pois estavam pobríssimos e eram muito poucos. Na mesma ocasião, em 10 de abril de 1617, escreveu Alonso Riquelme ao cabildo, cujas justiças eram Juan Fernandez Villalobos e Andrés Diaz de Rivera e também ao governador, remetendo-se a seus tenentes onde novamente afirmou:

Que estan rodeados de indios por conquistar y para maior trabajo rebelados los Itatines por lo que pedian les enviase para su guarda, los vezinos de la ciudad que andaban fuera. Que los portugueses entraron en su província, robaron los indios Taquari y se tenia por cierto volverian á la ciudad y al Itatin á destruir todas las encomendas. Que o padre Antonio Acosta se habia ido a S. Pablo com todos los indios de nacion Pinchumiai cuya fuga no se supo hasta los dos meses, por lo que se le siguió inutilmente mas de cien leguas. Se creia fuese cosa tratada com los portugueses pues fué su entrada al mismo tiempo que la ida del padre hacia ellos, mayormente cuando, segun los naturales, habia dos años que los portugueses entraron la primera vez. ${ }^{30}$

\footnotetext{
29 “Informe de um jesuíta anônimo sobre as cidades do Paraguai do Guairá espanhóis, índios e mestiços. Dezembro de 1620.” (In: CORTESÃO, Jaime (org.). Op. cit., vol. I, p. 169).

${ }^{30}$ AGUIRRE, J. F. Op. cit., p. 312.
} 
A catequese dos índios Guarani Itatins assentados no âmbito dos "Campos de Xerez”, resultou na constituição da Província Jesuítica do Itatim. No entanto, esclarece Martins $^{31}$, que as relações entre jesuítas, índios e colonos xerezanos, desde o início, não se deram de forma harmoniosa. Ao contrário, os jesuítas impuseram resistentes obstáculos à apropriação compulsória da mão-de-obra indígena catequizada, o que era, portanto, contraditório e incompatível com o modelo da economia colonial ibérica, baseada no sistema das encomiendas. ${ }^{32}$

Para Monteiro ${ }^{33}$, muito embora os jesuítas estivessem defendendo os interesses das metrópoles coloniais, a serviço dos reis católicos, acenavam com uma proposta alternativa de colonização que buscava, por meio dos aldeamentos e da catequese, transformar o índio em mão-de-obra produtiva. $\mathrm{O}$ aldeamento tinha como objetivo, além do trabalho de catequese e conversão dos indígenas nas Reduções, impedirem o acesso direto dos colonizadores a apropriação compulsória do trabalho indígena, método este que levava a escravização e conseqüentemente ao extermínio das populações autóctones de toda a América.

Cortesão ${ }^{34}$, ao apresentar o histórico das primeiras missões jesuíticas que se estabeleceram na província do Paraguai, catequizando os índios do Guairá e, a partir de 1632 os do Itatim, destacou o trabalho dos padres em Ciudad Real do Guairá, sobre o Paraná, em Vila Rica do Espírito Santo, sobre o Ivaí, e em Santiago de Xerez, sobre o Aquidauna. Para Cortesão o Guairá, Vila Rica e Xerez serviam como ponto de escala, ou seja, de passagem dos paulistas nas viagens em busca das sonhadas minas do Peru. Porém, afirma que é possível que nem todos os que iam ao Guairá ou até Vila Rica faziam a viagem ao Peru. Mas certamente os que passavam por Santiago de Xerez, atravessavam o Pilcomaio e o Guapaí e seguiam em direção às tais minas. ${ }^{35}$

Na compreensão apresentada por Esselin ${ }^{36}$ a fundação de Santiago de Xerez no Itatim está relacionada à busca de um caminho para o Peru na medida em que:

\footnotetext{
${ }^{31}$ MARTINS, Gilson Rodolfo. Op. cit.

${ }^{32}$ Idem, ibidem, p. 247. São Paulo: Cia. de Letras, 1994.

${ }^{34}$ CORTESÃO, Jaime. Raposo Tavares..., op. cit.

${ }^{35}$ Idem, ibidem, p. 291 e 297.

${ }^{36}$ ESSELIN, Paulo Marcos. Op. cit..
}

${ }^{33}$ MONTEIRO, Johan Manuel. Negros da terra: índios e bandeirantes nas origens de São Paulo: 
"As ligações comprovadas desse território com os Andes, através de diversas expedições, foram decisivas para o seu estabelecimento. Ficava a apenas quatrocentas léguas de Potosi e, apesar das dificuldades de acesso animava aos colonos a possibilidade de contatos com as regiões produtoras de metais" ${ }^{\prime 3}$.

Em uma petição do padre João Batista Ferrufino, de 1649, relatou o padre, ao ouvidor da província do Paraguai, Garabito de Leon, as dificuldades e os riscos em que se encontravam os poucos índios que haviam conseguido escapar das repetidas invasões que os portugueses de São Paulo faziam na província do Itatim. Afirmava o padre, que a nação Guarani, por ser uma das mais numerosas do Novo Mundo, se encontrava no momento consumida, acabada e despovoada. Os paulistas em suas incursões pela província do Guairá haviam aprisionado um grande número de índios, outros tentando fugir do assédio bandeirante preferiam seguir junto com os padres para outras regiões. Sendo assim, as muitas províncias do Paraguai, as quais se estendiam por milhares de léguas, se encontravam desfalcadas de seus habitantes nativos.

\section{Quanto ao despovoamento de Santiago de Xerez afirmou Ferrufino que:}

Descendiendo pues en particular a tratar de las invasiones, que na hecho en la Prova. de los Itatines, de que hablamos. notoria cosa es que el año de treinta y dos despoblaron los dhos Portugueses la ciudad de Jerez quitando a sus moradores los Indios de sus encomiendas que tenia en su servicio, y traiendo por guia a D. Diego de Orrego, que haciendo off ${ }^{\circ}$. de teniente en la dha ciudad de Jerez se entro entre ellos [entraron por la dicha Prova. de los Itatines] cautivando y llevando consigo gran parte de sus moradores, y destruieron cuatro pueblos, que avian começado a fundar los Padres Diego Ferrer, Justo Manzilla, Nicolas Enarcio, e Ignacio Martinez, que poco antes avian entrado en dar principio a la conversion de esta gentilidad, y al ultimo de los Padres referido le afligieron e trabajaron sobremanera, teniendole tres dias preso sin darle de comer, porque com liberdad les afeava, tan enormes desafueros. ${ }^{38}$

As bandeiras que assolaram o Guairá e também Santiago de Xerez partiam de São Paulo e contavam com a presença de muitos mamelucos e dezenas de índios auxiliares. Os tenentes dessas expedições eram comandados pelo mestre de

\footnotetext{
${ }^{37}$ Idem, ibidem, p. 48.

38 "Petição do Pe. João Baptista Ferrufino ao ouvidor Garabito para mudar os índios Itatim reduzidos para outro lugar. 1649”. In: CORTESÃO, Jaime (org.). Op. cit., vol. II, p. 78.
} 
campo Antônio Raposo Tavares, também identificado como cabo da tropa. Monteiro $^{39}$ afirma que ao sair de São Paulo, tinha esses expedicionários, um único objetivo: "aprisionar o maior número possível de índios os quais seriam utilizados como mão-de-obra compulsória em seus empreendimentos, alimentando, desta forma, uma crescente força de trabalho indígena que se fixava no planalto e era necessária para tocar os empreendimentos agrícolas dos paulistas" ${ }^{40}$.

No ano de 1628 partiu, então, de São Paulo, uma grande bandeira, a qual reuniu aproximadamente 900 mamelucos e 2.000 índios auxiliares, comandados por cerca de 70 paulistas. As bandeiras paulistas costumavam ser bianuais. No início do ano seguinte, 1629, adentraram a província do Guayrá, onde segundo o padre Montoya, afirmavam os paulistas, que estavam dispostos a expulsar os jesuítas, assim como expulsariam também a todos os espanhóis, que se encontravam naquela região, alegando que estavam estabelecidos em domínios territoriais que pertencia aos portugueses e não ao rei da Espanha. O vice-rei do Peru relatou a Filipe IV, em 1632, que os paulistas sustentavam ser legitimamente seu o território guairenho. Assim pretendia os portugueses expulsarem os jesuítas espanhóis do território do Guairá e reconquistar, para o Brasil, aquela região ocupada pelos castelhanos.

Affonso de E. Taunay ${ }^{41}$, ao examinar a documentação bandeirante faz uma importante consideração a esse respeito:

Fato curioso: o tom de toda essa documentação revela as circunstâncias de que ninguém considerava os paulistas como gente que fosse súdita do monarca espanhol. Tôdas estas denúncias apresentam estes acontecimentos como se em 1580 não houvesse ocorrido a integração de Portugal na monarquia dos Áustrias. Persistia como que a impressão nítida de que as relações das duas coroas eram pura e simplesmente as antigas dos tempos pós-aljubarrotanos. ${ }^{42}$

Diante dessas evidências, podemos perceber como a questão de limites territoriais entre Portugal e Espanha, no continente sul-americano, desde o seu início foi tenso e conflituoso. Tais conflitos resultaram em muitos descontentamentos,

\footnotetext{
${ }^{39}$ MONTEIRO, John Manuel. Op. cit.

${ }^{40}$ Idem, ibidem, p. 8.

${ }^{41}$ TAUNAY, Affonso de E. História das bandeiras paulistas. São Paulo: Melhoramentos, Tomo I, 1951

${ }^{42}$ Idem. ibidem, p. 62.
} 
desentendimentos, impasses e ações de espionagem por parte de ambas as metrópoles coloniais envolvidas, os quais se arrastaram por muito tempo. Somente com a assinatura do Tratado de Madri em 1750 é que se estabeleceram os limites territoriais entre as metrópoles coloniais ibérica no continente sul-americano.

Jaime Cortesão ${ }^{43}$ acredita que embora a União Ibérica possa ter propiciado algumas mudanças na política metropolitana, em relação às colônias da América, considera que essas mudanças foram bem menores e menos significativas, em suas amplitudes, do que costumam crer e afirmar alguns historiadores. Isso, segundo Cortesão, por desconhecerem as particularidades que regulamentaram essa união. Cortesão aceita o fato de que a união das duas coroas contribuiu de certa forma, para atenuar a acirrada oposição em que viviam anteriormente as duas monarquias ibéricas, pela posse das descobertas. Mas quanto às penetrações sociais e culturais entre Portugal e o Brasil e as províncias castelhanas da América, bem como o desejo alimentado pelos portugueses e platinos, de que a união das coroas peninsulares, sob o cetro filipino, fosse abrir-lhes francamente a região do Prata ao tráfico com o Brasil, tiveram suas expectativas frustradas. Porém, ressalta Cortesão que ganharam certo impulso as relações comerciais entre Buenos Aires e Santa Fé, de um lado e os portos brasileiros de outro. ${ }^{44}$

Sérgio Buarque de Holanda ${ }^{45}$, nos esclarece que, depois da fundação da segunda Buenos Aires, em 1580, data que coincide com o início da União Ibérica, os espanhóis, sim, passaram a se opor aos contatos comerciais que pudessem ser realizados pelo Prata, visando atingir o Peru por intermédio de Tucuman e Charcas, devido à concorrência que poderia oferecer Buenos Aires e a rota continental à clássica rota do Pacífico. "Pelo novo caminho sairiam prejudicados, não só o comércio de Sevilha com Terra Firme e o vice-reinado do Peru como a própria fazenda real, pois iria provocar ele uma autêntica sangria da prata e do ouro, especialmente da prata de Potosí, estimulando, além disso, o contrabando." ${ }^{\$ 4}$.

Discordando de Cortesão, Sérgio Buarque de Holanda enfatiza que a união das duas coroas permitiu sim maior aproximação e maiores contatos entre as

\footnotetext{
${ }^{43}$ CORTESÃO, Jaime. Jesuitas..., op. cit., v.1.

${ }^{44}$ Idem, ibidem. p. 76.

${ }^{45}$ HOLANDA, Sérgio Buarque. O extremo oeste. São Paulo: Brasiliense, 1986

${ }^{46}$ Idem, ibidem, p. 126.
} 
colônias sul-americanas espanholas e portuguesas, independentemente das determinações oficiais. Foi em consequência da União Ibérica, que os paulistas passaram a incursionar com mais facilidade e com mais frequência sobre as terras da Coroa de Castela, onde as guarnições militares eram muito poucas e as distâncias percorridas eram imensas. Considera ainda Holanda ${ }^{47}$, que na medida em que a colonização espanhola voltava suas atenções para o Peru, priorizando as atividades nas áreas produtoras de prata e ouro, atraída e fascinada pelos lucros com a mineração, ignorou e tratou com certa indiferença as demais regiões sobre seu domínio.

Promovendo incessantes ataques os bandeirantes paulistas apossaram-se das reduções de San Miguel, San Antonio, Jesus-Maria, Encarnacion, San Xavier e San José. Diante dos assaltos às suas Reduções, os padres reuniram em San Ignácio e Loreto os índios que conseguiram escapar das perseguições dos bandeirantes paulistas e abandonaram a província do Guayrá. Jesuítas e índios foram se estabelecer entre o Paraná e o Uruguai, onde já possuíam outras aldeias. Enquanto os jesuítas transferiam os índios para outro lugar, onde pudessem estar fora do alcance dos mamelucos de São Paulo, no ano de 1631 os bandeirantes se apoderavam dos povoados de Villa Rica e Ciudad Real destruindo-os completamente. Dessa forma, afirmam os missionários, que os paulistas destruíram com impiedade e crueldade nunca vista, uma das mais numerosas e prósperas províncias católicas. Mais de dez mil almas foram chacinadas, escravizadas e dispersas, havendo os de São Paulo conquistado mais de cem léguas da Coroa de Castela como se fora de algum rei estranho ou inimigo, agindo como se desconhecessem, de fato, a União das duas Coroas.

Examinando a documentação referente ao período estudado, encontramos denúncias feitas pelo governador de Buenos Aires, D. Pedro de Estevão Davila, contra os graves danos causados pelos paulistas a província do Paraguai. Afirmou Davila que:

[...] llegado que fui al Rio de Janero vi y reconoci ser cierta la relacion que se me avia hecho pues a mis ojos se vendian los indios en aquella Ciudad traydos por los vezinos de la villa de San Pablo, como si fueran esclavos y dados por tales por V. M. e ynformado vine averiguar vervalmente como desde el ano de

\footnotetext{
${ }^{47}$ Idem, ibidem.
} 
28 hasta de 30 avian traydo los vezinos de San Pablo mas de setenta mil almas de las reduciones de los Padres de la compañia del destrito de este govierno y del del Paraguay, en que havian usado los dichos vezinos de San Pablo crueldades y inhumanidades increybes hasta faltar en sus acciones a catolicos Xptianos. ${ }^{48}$

No ano de 1632, após capturarem e aprisionarem um grande número de índios e saírem vitoriosos do Guairá, os bandeirantes paulistas voltaram-se para o sul de Mato Grosso, para o Itatim, como se dizia, onde se encontrava estabelecido o núcleo colonial urbano de Santiago de Xerez. $\mathrm{Na}$ ocasião dessas invasões, os bandeirantes renderam os moradores de Xerez os quais, diante da precária circunstância em que se encontravam, passaram a colaborar com os portugueses, na invasão aos demais povoados indígenas do Itatim. Os xerezanos seguiram junto aos bandeirantes aterrorizando e aprisionado um grande número de índios. Os padres da Companhia de Jesus se referiam aos paulistas como se fossem verdadeiros dragões devoradores de todas aquelas terras, utilizando-se das armas que melhor sabiam manejar: o engano e a mentira.

Na ocasião dessas invasões:

[...] os paulistas transpondo o alto Paraná, não só tomaram Santiago de Xerez, estabelecimento espanhol, sito perto das nascentes do Aquidauana, como também destruíram as três reduções de San José, Angeles e San Pedro e San Pablo, que os jesuítas tinham acabado de formar, com índios Itatins, a oeste do rio Pardo, no atual Estado de Mato Grosso. Alguns castelhanos, moradores em Xerez, e que estavam de boa avença com os bandeirantes passaran-se nessa ocasião para São Paulo. ${ }^{49}$

Os moradores das cidades despovoadas pelos bandeirantes, entre elas, Vila Rica e Ciudad Real no Guairá e Santiago de Xerez no Itatim, ao constatarem que haviam perdido seus índios, suas casas e suas fazendas, e que, naquele momento, se encontravam em desvantagens para resistir, se viram obrigados a seguir junto com os paulistas para São Paulo, ao invés de buscarem refúgio ou proteção em

\footnotetext{
${ }^{48}$ Representação do Governador de Buenos Aires, D. Pedro Estevão Davila, a Felipe IV em que denuncia os graves danos causados pelos paulistas à província do Paraguai e propõe os meios para remediá-los 12- X - 1637. In: CORTESÃO, Jaime (org.). Op. cit., vol. II, p. 61.

${ }^{49}$ MAGALHÃES, Basílio. “Expansão geográfica do Brasil até fins do século XVII”. In: Revista do Instituto Históricoe Geográfico Brasileiro. Rio de Janeiro. Tomo Especial. Parte II, 1914. p. 102.
} 
Assunção. Segundo Diogo Ferrer, vários foram os motivos para que os espanhóis de Xerez seguissem com os paulistas. Em sua Carta Ânua de 1633, assim se referiu ao fato em questão: "y como com los Portuguezes venian los Españoles de Xerez los quales unos por miedo que tenian de los Portuguezes, otros por averse del todo ya entregado a ellos, afirmavan lo mismo, facil foi persuadir a los indios en ausencia del Pe. que fuessen com ellos a pelear contra sus hermanos." 50

Devido aos constantes ataques bandeirantes que se seguiram e se intensificaram por toda a região do Guairá e dos Campos de Xerez, a partir de 1628, o fato é que pouco tempo depois do despovoamento da província do Guairá, acontecia a ruína e o despovoamento de Santiago de Xerez, a qual também foi vítima dos ataques dos mamelucos de São Paulo. Em uma informação citada pelo procurador Francisco Sanchez Cabrera, consta que o povoado de Xerez foi surpreendido e seus moradores foram presos. Na ocasião o general D. Martin de Ledesma Valderrama ao saber da entrada dos paulistas em Xerez, enviou uma armada sobre o comando dos capitães Cristobal Ramires e Felipe de Torrillas e Linares para que fossem prestar socorro aos xerezanos. Contudo, quando a expedição chegou a Xerez, não conseguiu alcançar os invasores, os quais já haviam se retirado levando muitos índios por prisioneiros. ${ }^{51}$

No ano de 1632, as bandeiras paulistas, que desde a primeira metade do século XVII, haviam iniciado suas investidas em direção aos territórios de domínio espanhol, após destruir o Guairá, invadiram Santiago de Xerez. Afirma Costa ${ }^{52}$, que os bandeirantes invadiram Xerez, mas não a destruíram, ao contrário do que afirmam alguns historiadores. "São os seus miseráveis habitantes que, ao sentirem a aproximação dos paulistas, resolvem abandoná-la. Coincidentemente, foi nesse mesmo ano de 1632 que os jesuítas estabeleceram suas missões no Itatim" $" 53$.

50 Ânua do Pe. Diogo Ferrer para o Provincial sôbre a Geografia e Etnografia dos indígenas do Itatim VIII - 1633. In: CORTESÃO, Jaime (org.). Op. cit., vol. II, p. 39.

${ }^{51} \mathrm{O}$ documento segue afirmando que, muito embora a ajuda enviada tenha chegado tarde em Xerez, mesmo assim foi de grande utilidade porque no caminho reconheram alguns índios que se encontravam dispersos e com eles fundararam outros dois povoados. Um se chamou São Benito e o outro Nossa Senhora da Fé. Nesses dois novos povoados atuaram dois jesuítas que se encontravam junto aos índios quando se deu o despovoamento de Xerez. AGUIRRE. J. F. Op. cit., p. 391.

${ }^{52}$ COSTA, Maria de Fátima. Op. cit.

${ }^{53}$ Idem, ibidem, p. 45. 
Diante das evidências históricas apresentadas consideramos que o Paraguai passou então a vivenciar um novo momento em sua história. Após o despovoamento de Santiago de Xerez pelos espanhóis em 1632, os portugueses se estabeleceram na região. No entender de Juan Francisco de Aguirre, responsável pelos trabalhos de demarcação dos limites das terras da Coroa espanhola na América do sul, ao analisar criteriosamente o material histórico disponível, considerou que o abandono pelos espanhóis das posições que já ocupavam, tanto no Guairá como em Xerez resultou não de seu pouco valor, mas sim de sua pouca vontade de lutar. Afirma Aguirre que os espanhóis que deixaram o Guairá não tinham outro pensamento senão o de se irem daquelas terras e procurarem melhor vida. Considerou este que os assaltos dos paulistas serviram apenas como um pretexto. Aguirre admite também que Assunção encarava com indiferença o abandono das terras já povoadas e nem deu qualquer passo para defendê-las da fúria lusitana.

Ao comentar essa indiferença, sugerida por Aguirre, Sergio Buarque de Holanda ${ }^{54}$, afirma em suas considerações que:

[...] se essa indiferença era de lamentar no caso do Guairá, tornara-se imperdoável no tocante a Xerez. Só depois de descobertas as riquezas minerais do Cuiabá e do Mato Grosso, que caíram em mãos de portugueses, puderam os assuncenhos reconhecer os prejuízos irreparáveis que vieram a sofrer por não reconhecerem em tempo a importância daquele estabelecimento, situado junto ao Mbotetei, que os mamelucos puderam impunemente destruir em $1632^{55}$.

De acordo com as fontes consultadas foi possível verificar que a partir de 1620 se intensificaram os ataques dos bandeirantes luso-paulistas sobre a região das antigas províncias do Guairá e do Itatim. Com o abandono de Santiago de Xerez pelos colonos xerezanos, na ocasião do ataque bandeirante de 1632, o domínio espanhol sobre a região se tornou cada vez menor. No ano de 1750 quando se deu a assinatura do Tratado de Madri, o qual adotou o uti possidetis como critério para estabelecer os limites territoriais entre Portugal e a Espanha na América do Sul, o Paraguai Católico Colonial, na expressão de Sanches Labrador sofreu uma drástica redução. Todo o território do atual Mato Grosso do Sul passou efetivamente ao domínio português, pois eram estes que se encontravam estabelecidos na região em 1750 quando o Tratado foi ratificado.

\footnotetext{
${ }^{54}$ HOLANDA, Sergio Buarque de. Op. cit.

${ }^{55}$ Idem, ibidem, p. 97.
} 
Consideramos que ao voltarmos nossas atenções para o estudo do período colonial brasileiro, particularmente para a montagem das etapas iniciais, buscamos compreender quais foram as circunstâncias históricas em que se deu a presença colonial espanhola, na região do atual Estado de Mato Grosso do Sul. Partimos da premissa de que os fenômenos descritos com imprecisões e contradições são os que precisam ser questionados, investigados e revisitados, para que dessa forma possamos ter condições de esclarecer e entender as particularidades da conquista e o início da colonização desse espaço regional, o sul de Mato Grosso colonial. 